\title{
DAMPAK ETNOSENTRIME DAN BUDAYA POPULER TERHADAP SIKAP KONSUMEN SERTA IMPLIKASINYA TERHADAP MINAT BELI KONSUMEN
}

\author{
Sumiati \\ Program Studi Magister Manajemen Universitas Tarumanagara \\ sumiati_101@yahoo.com
}

Masuk : 14-06-2019, revisi : 22-08-2019 diterima untuk diterbitkan : 23-08-2019

\begin{abstract}
The purpose of this study is to analyze the impact of ethnocentrism, and korean wave toward attitude and implications to purchase intention for product cosmetic korea in Indonesia. This paper used quantitative method using Structural Equation Modeling (SEM) using AMOS 20 software. In total, 195 respondents completed a questionnaire were used Likert Scale with 1-5 score. The results of this study showed consumer ethnocentrism have negative significant impact on Attitude and purchase intention, Korean wave have postive significant impact on Attitude and purchase intention and Attitude have postive significant impact on Purchase Intention.
\end{abstract}

\begin{abstract}
Abstrak : Penelitian ini bertujuan untuk menganalisis pengaruh etnosentrisme dan budaya populer korean wave terhadap sikap dan minat beli konsumen terhadap produk kosmetik korea. Penelitian ini menggunakan metode kuantitatif dengan metode survei menggunakan kuisioner yang disebarkan kepada 195 responden. Data dianalisis menggunakan metode Structural Equation Modelling (SEM) dengan aplikasi AMOS 20. Hasil analisis menunjukkan bahwa etnosentrisme berpengaruh signifikan negatif terhadap sikap dan minat beli konsumen sedangkan budaya populer berpengaruh signifikan positif terhadap sikap dan minat beli konsumen dan sikap konsumen juga berpengaruh signifikan positif terhadap minat beli konsumen.
\end{abstract}

Keywords : Ethnocentrism, Korean Wave, Attitude, Purchase Intention, Cosmetic Korea, SEM (Structural Equation Modeling)

\section{PENDAHULUAN}

Produk kecantikan sudah tidak hanya merupakan kebutuhan bagi para wanita tetapi seiring berlanjutnya waktu, produk kosmetik juga sudah berinovasi untuk kaum pria dan anakanak. Pada dekade 1990an produk kosmetik yang diminati mayarakat Indoesia masih cenderung berasal dari negara barat seperti Amerika dan Eropa namun semenjak adanya pengaruh budaya korea yang secara langsung maupun tidak langsung mempengaruhi masyarakat Indonesia, produk kecantikan asal korea juga mulai mengambil bagian yang sangat besar industri kecantikan Indonesia

Indonesia merupakan salah satu pangsa pasar berpotensial besar bagi Korea selatan dalam memasarkan produk kecantikannya salah satu alasannya dikarenakan Indonesia adalah negara dengan nominal fanbase Korean Wave terbesar di dunia dan hal ini akan menjadi suatu permasalahan serius yang akan mengancam industri kosmetik dalam negeri.

Budaya korea wave ini masuk ke Indonesia menyebabkan perubahan yang signifikan bagi masyarakat mulai dari pola berpikir, perilaku, gaya hidup masyarakat bahkan mempengaruhi cara perilaku masyarakat dalam melakukan keputusan pembelian sebuah produk oleh karena itu pemahaman terhadap karakteristik konsumen menjadi salah satu kunci yang penting. Salah satu karakter konsumen yang perlu dipahami oleh produsen kosmetik lokal dalam menghadapi persaingan dengan produk-produk kecantikan asal korea ini adalah sikap etnosentrisme. 
Consumer Ethnocentrism dapat mempengaruhi perilaku pembelian konsumen baik pada pemilihan produk lokal atau produk impor. Seseorang yang yang etnosentris cenderung berpengaruh positif terhadap produk domestiknya (Evanschitzky et al., 2008) dan menurut Shimp dan Sharma (1987) konsumen yang memiliki kecenderungan etnosentris akan merasa takut untuk membeli produk impor, karena adanya faktor moral dan personal prejudice yang akan diletakkan oleh kelompok masyarakatnya.

Tingkat Etnosentrisme seseorang dan faktor budaya korea wave akan mempengaruhi sikap konsumen terhadap suatu produk dan menjadi pertimbangan dalam melakukan proses konsumsi. Tujuan dari penelitian ini adalah untuk mengetahui pengaruh etnosentrisme konsumen dan budaya korean wave terhadap sikap konsumen dan implikasinya kepada minat beli konsumen terhadap produk kosmetik korea.

\section{TINJAUAN PUSTAKA}

Konsep Ethnocentrism ini pertama kali diperkenalkan oleh sumner (1906) dan kemudian diperluas oleh Shimp dan Sharma (1987) dengan menghubungkan konsep Ethnocentrism dengan konsep pemasaran yaitu dengan perilaku konsumen yang dikenal dengan istilah Consumer Ethnocentrism yang berarti keyakinan konsumen Amerika tentang moralitas dan kepantasan pembelian produk buatan luar negeri. Shimp dan Sharma (1987) mengembangkan instrumen untuk mengukur tingkat sentimen etnosentrisme konsumen tersebut yang disebut CETSCALE (Consumer Ethocentric Tendencies Scale).

Budaya populer yang saat ini sedang melanda berbagai negara terutama Negara-negara di Asia adalah budaya yang berasal dari Korea Selatan. Korea saat ini tengah membentuk mainstream baru di berbagai negara melalui K-pop (musik pop Korea), serial drama, film dan video game. Kesuksesan budaya pop Korea ini terbukti dengan munculnya istilah "The Korean Wave" sebagai seberapa fenomena budaya pop Korean yang disebarkan.

Sikap menurut Schiffman dan Kanuk (2004) merupakan ekspresi perasaan yang berasal dari dalam individu yang mencerminkan apakah seseorang senang atau tidak senang, suka atau tidak suka dan setuju atau tidak setuju terhadap suatu objek.

Menurut Kotler (2008) minat beli konsumen adalah sesuatu yang timbul setelah menerima rangsangan dari produk yang dilihatnya, dari sana timbul ketertarikan untuk mencoba produk tersebut sampai pada akhirnya timbul keinginan untuk membeli agar dapat memilikinya.

Berdasarkan uraian variabel diatas maka dapat disimpulkan hipotesis pada penelitian ini adalah sebagai berikut :

$\mathrm{H}_{1}=$ Terdapat hubungan signifikan Etnosentrisme Konsumen terhadap Attitude sikap konsumen terhadap produk kosmetik korea

$\mathrm{H}_{2}=$ Terdapat hubungan signifikan Etnosentrisme Konsumen terhadap minat beli konsumen terhadap produk kosmetik korea

$\mathrm{H}_{3}=$ Terdapat hubungan signifikan Budaya Korean Wave terhadap Attitude sikap konsumen terhadap produk kosmetik korea

$\mathrm{H}_{4}=$ Terdapat hubungan signifikan Budaya Korean Wave terhadap minat beli konsumen terhadap produk kosmetik korea

$\mathrm{H}_{5}=$ Terdapat hubungan signifikan Sikap konsumen terhadap minat beli konsumen terhadap produk kosmetik korea 


\section{KERANGKA PENELITIAN}

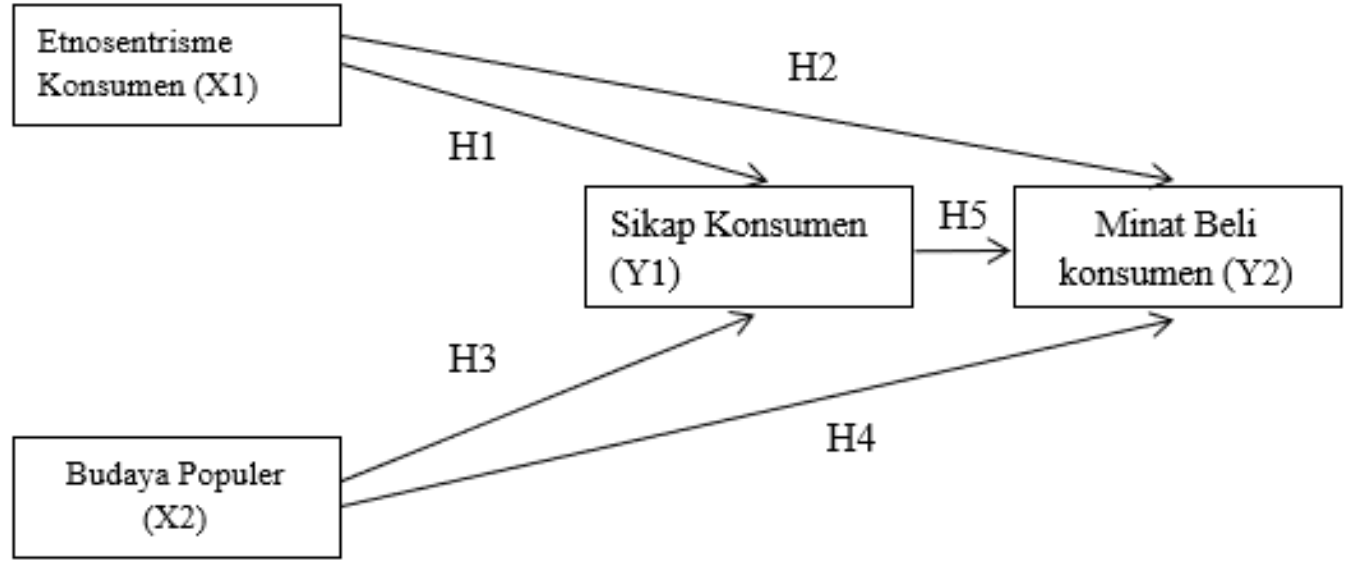

Gambar 1

Kerangka penelitian

\section{METODE PENELITIAN}

Jenis Penelitian yang akan dilakukan yaitu dengan pendekatan kuantitatif deskriptif, Data primer dari penelitian tersebut akan diperoleh dengan cara menyebarkan kuesioner dengan metode convenience sampling sebanyak 195 kuesioner. Untuk jawaban dari responden akan diukur dengan skala Likert. Skala ini mengukur sikap, pendapat, dan persepsi seseorang atas sebuah fenomena, Sugiyono (2013). Skala likert akan memberikan kemudahaan dalam menyusun suatu penelitian dengan mengurutkan skor berdasarkan sikap tertentu dari responden.

Teknik analisis yang digunakan pada penelitian ini adalah stuctural equation modelling (SEM) Pengolahan data dengan menggunakan bantuan software AMOS 20.

\section{OPERASIONALISASI VARIABEL}

Operasional variabel ini bertujuan untuk memberi batasan kepada variabel yang terkait dengan penelitian sehingga variabel dapat diukur dan agar kuisioner yang disusun dapat mencerminkan masalah dari model penelitian yang digunakan.

Tabel 1

Variabel Penelitian

\begin{tabular}{|c|c|c|c|}
\hline Variabel & Definisi & Indikator & Keterangan \\
\hline $\begin{array}{l}\text { Etnosentrisme } \\
\text { Customer } \\
\text { (X1) }\end{array}$ & $\begin{array}{l}\text { Keyakinan konsumen } \\
\text { tentang moralitas dan } \\
\text { kepantasan pembelian } \\
\text { produk buatan luar } \\
\text { negeri. }\end{array}$ & $\begin{array}{l}\text { 1. First (X1.1) } \\
\text { 2. Purchase (X1.2) } \\
\text { 3. Jobs (X1.3 } \\
\text { 3. Rich (X1.4) } \\
\text { 4. Obtain (X1.5) } \\
\text { 5. Work (X1.6) }\end{array}$ & $\begin{array}{l}\text { Shimp and } \\
\text { Sharma, } 1987 \\
\text { Klein et al, } \\
1998\end{array}$ \\
\hline $\begin{array}{l}\text { Budaya } \\
\text { popular/ } \\
\text { Korean Wave } \\
\text { (X2) }\end{array}$ & $\begin{array}{l}\text { Fenomena budaya pop } \\
\text { Korean yang disebarkan }\end{array}$ & $\begin{array}{l}\text { 1. Pemahaman } \\
\text { 2. Sikap dan perilaku } \\
\text { 3. Persepsi }\end{array}$ & $\begin{array}{l}\text { Lita and Cho } \\
\text { (2012) }\end{array}$ \\
\hline $\begin{array}{l}\text { Sikap } \\
\text { (Attitude } \\
\text { customer) } \\
\text { (Y1) }\end{array}$ & $\begin{array}{l}\text { Ekspresi perasaan yang } \\
\text { berasal dari dalam } \\
\text { individu yang } \\
\text { mencerminkan apakah } \\
\text { seseorang senang atau }\end{array}$ & $\begin{array}{l}\text { 1. Kognitif } \\
\text { 2. Afektif } \\
\text { 3. Konatif }\end{array}$ & $\begin{array}{l}\text { Shiffman and } \\
\text { Kanuk (2004) }\end{array}$ \\
\hline
\end{tabular}




\begin{tabular}{|l|l|l|l|}
\hline & $\begin{array}{l}\text { tidak senang, suka atau } \\
\text { tidak suka dan setuju } \\
\text { atau tidak setuju } \\
\text { terhadap suatu objek. }\end{array}$ & & \\
\hline $\begin{array}{l}\text { Purchase } \\
\text { Intention } \\
(\text { Y2) }\end{array}$ & $\begin{array}{l}\text { sesuatu yang timbul } \\
\text { setelah menerima } \\
\text { rangsangan dari produk } \\
\text { yang dilihatnya, dari } \\
\text { sana timbul ketertarikan } \\
\text { untuk mencoba produk } \\
\text { tersebut sampai pada } \\
\text { akhirnya timbul } \\
\text { keinginan untuk } \\
\text { membeli agar dapat } \\
\text { memilikinya }\end{array}$ & $\begin{array}{l}\text { 1. Minat transaksional } \\
\text { 2. Minat refrensial } \\
\text { 3. Minat preferensial } \\
\text { 4. Minat eksploratif }\end{array}$ & $\begin{array}{l}\text { Ferdinand } \\
(2006)\end{array}$ \\
\hline
\end{tabular}

\section{HASIL DAN PEMBAHASAN}

Kesesuaian model SEM pada penelitian ini diukur dengan menggunakan pengujian Goodness of Fit. Pada tabel 2 dapat dilihat hasil pengujian Goodness of Fit dari keseluruhan model (overall model fit) penelitian telah dipenuhi dengan aplikasi AMOS.

Tabel 2

Hasil Pengujian Goodness of Fit

\begin{tabular}{|c|c|c|c|}
\hline Goodness of Fit Indices & Cut of Value & Hasil Model & Keterangan \\
\hline$X^{2}$ Chi Square & Diharapkan kecil & 168,689 & Good Fit \\
\hline Probabilitas & $\geq 0.05$ &, 000 & Tidak Fit \\
\hline RMSEA & $\leq 0.08$ & 0,072 & Good Fit \\
\hline GFI & $\geq 0.90$ & 0,897 & Good Fit \\
\hline AGFI & $\geq 0.90$ & 0,853 & Marginal \\
\hline CMIN/DF & $\leq 2.0$ & 2,008 & Marginal \\
\hline TLI & $\geq 0.90$ & 0,932 & Good Fit \\
\hline CFI & $\geq 0.90$ & 0,946 & Good Fit \\
\hline
\end{tabular}

Setelah data telah memenuhi asumsi-asumsi SEM maka dapat dilakukan analisis terhadap hubungan structural (pengujian hipotesis). Pengujian hipotesis ini dengan cara menganalisis nilai Critical Ratio (CR) dan nilai Probability $(\mathrm{P})$ yang ditampilkan pada bagian Regression Weights Analisis Structural Equation Modeling pada program AMOS Apabila nilai CriticalRatio (c.r) $\geq 1,96$. Atau nilai probabilitas $(\mathrm{P}) \leq 0,05$ maka hipotesis penelitian diterima.

Tabel 3

Hasil pengujian Hipotesis

\begin{tabular}{|llllllll|}
\hline & & & Estimate & S.E. & C.R. & P & Keterangan \\
\hline Sikap & $<--$ & Etnosentrisme & $-0,371$ & 0,084 & $-4,433$ & $* * *$ & Signifikan \\
Sikap & $<--$ & Budaya & 0,444 & 0,068 & 6,535 & $* * *$ & Signifikan \\
Minatbeli & $<--$ & Etnosentrisme & $-0,261$ & 0,086 & $-3,04$ & 0,002 & Signifikan \\
Minatbeli & $<--$ & Budaya & 0,276 & 0,079 & 3,5 & $* * *$ & Signifikan \\
Minatbeli & $<--$ & Sikap & 0,707 & 0,121 & 5,85 & $* * *$ & Signifikan \\
\hline
\end{tabular}




\section{KESIMPULAN DAN SARAN}

Berdasarkan hasil pengujian hipotesis yang di dapatkan maka kesimpulan dari penelitian tersebut adalah sebagai berikut:

1. Etnosentrisme berpengaruh negatif signifikan terhadap sikap konsumen dalam menghadapi produk impor

2. Etnosentrisme berpengaruh negatif signifikan terhadap minat beli konsumen dalam menghadapi produk impor

3. Budaya Korean Wave berpengaruh postif signifikan terhadap sikap konsumen dalam menghadapi produk impor

4. Budaya Korean Wave berpengaruh postif signifikan terhadap minat beli konsumen dalam menghadapi produk impor

5. Sikap konsumen berpengaruh postif signifikan terhadap minat beli konsumen

Berikut ini ada beberapa saran dari peneliti antara lain :

1. Disarankan kepada para pengusaha lokal dalam bersaing melawan produk impor dapat melakukan upaya peningkatan etnosentrisme konsumen bisa dengan cara menambahkan label seperti made by Indonesia atau kata-kata aku cinta Indonesia pada kemasan produk sehingga dapat meningkatkan kesadaran konsumen Indonesia untuk mengutamakan membeli dan menggunakan produk Indonesia dan membantu dalam meningkatkan pertumbuhan perekonomian Indonesia.

2. Untuk para peneliti selanjutnya diharapkan dapat lebih cermat dan teliti pada saat melaksanakan penelitian yang berkaitan dengan minat beli sehingga dapat mengetahui dengan pasti faktor terbesar yang mendorong konsumen melakukan pembelian, kemudian menambahkan faktor lain selain faktor pada penelitian ini.

3. Peneliti juga merekomendasikan pada peneliti selanjutnya yang akan mengambil objek penelitian yang sama sebaiknya dapat memperluas jangkauan penelitian dan memperbanyak jumlah sampel, serta menambahkan pilihan data responden selain usia, penghasilan dan tingkat pendidikan.

\section{DAFTAR PUSTAKA}

Evanschitzky, H., Wangenheim, F. V., Woisetschla, D. and Blut, M. (2008), Consumer ethnocentrism in the German market, International Marketing Review

Ferdinand, Augusty. 2006. Metode Penelitian Manajemen. Badan Penerbit Universitas Diponegoro. Semarang.

Klein, J. G., \& Richard Ettenson and Marlene D. Morris. (1998). The Animosity Model of Foreign Product Purchase: An Empirical Test in the People's Republic of China. Journal of Marketing, Vol. 62, 89-100.

Kotler, Philip. 2008. Manajemen Pemasaran Edisi 12 Jilid 2. Jakarta: Indeks

Lita, Rahmiati \& Yoon C. Cho. 2012. The Influence of Media on Attitudinal and Behavioral Changes: Acceptance of Culture and Products. Korea: KDI School of Public Policy and Management.

Schiffman dan Kanuk. 2004. Perilaku Konsumen Edisi Ketujuh. Jakarta: Salemba Empat.

Shimp, T.A. and Sharma, S. (1987), "Consumer ethnocentrism: construction and validation of the CETSCALE', Journal of Marketing Research.

Sugiyono. 2013. Metode Penelitian Pendidikan Pendekatan Kuantitatif, Kualitatif, dan R\&D. Bandung: Alfabeta. 